\title{
EL ENSAYO Y LA INVESTIGACIÓN EN HUMANIDADES
}

\author{
María Eugenia Góngora \\ Decana \\ Facultad de Filosofía y Humanidades, Universidad de Chile
}

Como una manera de contribuir a un debate que me parece necesario, quiero referirme al tema del reconocimiento del ensayo y de la investigación en el campo de las humanidades y, en directa relación con este reconocimiento, a los criterios prevalentes en la evaluación curricular en el ámbito académico chileno, tal como ella se ha instalado en las universidades y en las instituciones que distribuyen fondos públicos para la investigación ${ }^{1}$.

Como lo han destacado en nuestro medio Carlos Ossandón, Cecilia Sánchez, entre otros, y muy recientemente José Santos Herceg ${ }^{2}$, es importante hacer

\footnotetext{
Creo que es necesario recordar que, si bien en la Universidad de Chile se ha realizado un esfuerzo por valorar la diversidad y especificidad de la investigación en las humanidades, las ciencias sociales y las artes, el tema no es tan claro en los grupos de estudios en Fondecyt. Si revisamos algunos de los grupos relevantes para las humanidades, nos encontramos con una situación dispar al revisar las pautas de evaluación para el concurso 2013. En los grupos de estudios de filosofía e historia se ha elevado significativamente el puntaje de los libros (20 puntos para libros editados con referato externo) en relación a los artículos ISI/Scopus (10 puntos), si comparamos estos puntajes con los de períodos anteriores. Sin embargo, en el grupo de lingüística, literatura y filología se conserva todavía una asignación de 10 puntos para un artículo ISI/Scopus, mientras solo se asignan 15 puntos para un libro con referato externo y 7 puntos respectivamente para un libro con referato interno y Comité Editorial, como sucede en los otros grupos de estudio mencionados.

2 José Santos Herceg. "La Tiranía del paper. Imposición Institucional de un tipo discursivo". Revista Chilena de Literatura nº 82 (noviembre de 2012): 197-217; Sánchez, Cecilia, "Institucionalidad de la filosofía: entre la reflexión y el conocimiento productivo". Mapocho 67 (2010): 373-385; Carlos Ossandón, documento interno de trabajo, Facultad de
} 
manifiesta la necesaria e inevitable tensión entre la creatividad y la reflexión en humanidades y la llamada profesionalización de la investigación académica ${ }^{3}$. Me refiero en particular a la evaluación curricular de los artículos científicos y de los libros, especialmente de aquellos escritos, ya sean libros o artículos, que tienen la estructura más o menos abierta de un ensayo.

En el marco de un intento mayor de estandarización de las actividades de investigación, en gran medida empujadas por la necesidad de competir en rankings y de postular a fondos concursables, las autoridades universitarias afirman la necesidad de que esas actividades estén cada vez más determinadas por el tipo de formato en el cual se pueda 'demostrar' su validez en términos universalmente reconocidos, más allá de todos los parámetros de calidad más informales o locales, como por ejemplo, las reseñas propias de la crítica académica.

En este sentido, las exigencias de rendimiento prefiguran, como lo ha planteado Carlos Ossandón, un tipo de "autor" y de "autoridad"; esas exigencias "alimentan las revistas de corriente principal, articulan temas y saberes, se ciñen a un formato que no se ve particularmente idóneo para apuestas o experimentaciones"4 y se alejan claramente del tipo de escritura que habitualmente llamamos 'ensayo', en el que, a partir de la exposición de un problema, se construye y se propone una determinada interpretación del objeto de estudio.

Lo que me parece importante de señalar aquí es que no debemos olvidar que el paper es un formato en evolución y que, como tal, está históricamente situado en la academia norteamericana, básicamente a partir de los años sesenta; por lo mismo, está sujeto también a la reflexión y a la crítica. Dicho de otra manera, y aunque es perfectamente legítimo como formato de comunicación, el

Filosofía y Humanidades, 2010, publicado luego en Ossandón B., Carlos. "Investigación en Humanidades. Escrituras y Protocolos". Debates Críticos, Universidad Arcis, Santiago, ${ }^{\circ} 2$ (2011): 36-38.

En una consideración amplia sobre el concepto del "desarrollo" desde la filosofía, Pablo Oyarzún ha destacado la importancia de la reflexión y su relación con la 'productividad' propia de una cierta visión del desarrollo, planteando también la importancia de la reflexión como actividad humana improductiva, sin la cual no es posible "ninguna empresa educativa ni tampoco construcción cultural alguna". Oyarzún, Pablo. "Es necesario tener una visión amplia del desarrollo". Revista Docencia, 2003.

http://www.revistadocencia.cl/pdf/20100730163650.pdf (última visita, 20.04.13)

$4 \quad$ Cf. Carlos Ossandón, documento de trabajo, 2010. 
paper no es una forma de articulación "natural" de las ideas y del lenguaje, ni la única manera de comunicar la reflexión, el conocimiento, y la investigación. Como sabemos, el artículo que se presenta en nuestro medio a publicaciones indexadas en ISI $u$ otros es un texto preferentemente breve, al que se le exige una máxima focalización temática (las grandes síntesis no son bienvenidas), un dominio del 'estado del arte' y en el cual el sistema de citas, por ejemplo, está sujeta a un conjunto de normas periódicamente actualizadas. Por otra parte, el texto debe estar acompañado de palabras clave y de un resumen que, desde donde quiera que se escriba el artículo, debe estar acompañado de una versión inglesa del mismo.

Hay que reconocer que la valoración de los papers en su contexto académico se ha convertido en un círculo virtuoso. El ingreso de un artículo al circuito de una publicación ISI (y más recientemente a Scopus) permitirá verificar, y esto es fundamental en este tema, el así llamado "impacto". La cantidad de citas es un factor que incidirá a su vez en las posibilidades de los autores de postular a nuevos fondos, gracias justamente a su pertenencia a este circuito. En cuanto a la calidad de su aporte, se la supone garantizada por la labor de los comités responsables de las revistas donde se ha publicado el artículo.

\section{DESDE LAS HUMANIDADES}

Como ha escrito Carlos Ossandón en relación con los que cultivan las humanidades: “... despojados del lugar que se tenía en el terreno de la acción comunicativa, no contando hoy con los prestigios letrados de antaño, no es extraño que estos académicos dirijan sus investigaciones y publicaciones hacia aquellos temas o espacios donde pueden obtener resultados tangibles, objetivos"5 y fácilmente reconocidos en el medio académico.

En este mismo sentido, es bueno recordar que, en el campo de las humanidades, los investigadores han dispuesto históricamente de variados soportes y formatos para comunicar sus propuestas de lectura, la reflexión cultural y los resultados de su investigación en estas áreas. Por otra parte, es también relevante preguntarse si la figura del "autor" de un estudio histórico, filosófico o literario tiene o no características diferentes de las del autor de un artículo científico que comunica el resultado de una operación de otro orden. 
Pensemos en esos 'productos' (para usar una palabra inconveniente) de las humanidades, hasta el día de hoy, y que son, en términos muy generales, los que acabamos de mencionar, el estudio histórico y filosófico, la revisión crítica de los géneros literarios, el estudio filológico, la crítica cultural. Todos ellos se basan, sin duda, en una forma específica de investigación y de reflexión y están sujetos a fuertes exigencias de rigor argumentativo y de pertinencia en sus respectivos campos. Por su especificidad disciplinaria, no me parece posible afirmar que el formato más apropiado para comunicar esos trabajos de largo aliento sea únicamente el de un artículo ni aún un conjunto de artículos como los que últimamente se tienden a publicar en forma de libro.

Me parece también necesario mencionar, en el contexto de esta discusión, que en el campo de las humanidades, aquellos académicos que han culminado su carrera se sienten mucho más libres de las constricciones del medio: publican preferentemente libros y ensayos e incluso, cuando escriben un artículo, se sienten libres de publicarlo en revistas que no necesariamente son ISI, pero que forman parte de una red académica y cultural respetada en el campo de su disciplina.

En otras palabras, es la necesidad de producir para competir y para ascender en la carrera académica la que más obliga a la escritura en aquellos formatos que, desde otras disciplinas, se consideran ahora prácticamente los únicos válidos, puesto que, desde el punto de vista de aquéllos que, por su tradición disciplinaria no escriben libros, éstos son considerados productos demasiado "generalistas" y poco "científicos", demasiado "libres", en otras palabras, como para considerarlos importantes en la evaluación curricular académica.

Creo necesario recordar también que estamos hablando desde Chile y en el marco de la tradición latinoamericana, cosa que tiende a olvidarse cuando, en el afán de formar parte del 'primer mundo' académico, adoptamos la lógica de los rankings, todos ellos necesariamente globalizados y globalizantes, sin considerar en qué consiste verdaderamente nuestro aporte propio, con sus especificidades, sus fortalezas y debilidades. Es importante recordar siempre de nuevo que, en América Latina y en el Caribe, la tradición del discurso ensayístico tiene todavía fuerza y se ha adaptado a múltiples circunstancias históricas. Por esas razones, al menos en el ámbito de las humanidades y de las ciencias sociales, el ensayo conserva en nuestro ámbito algo del antiguo prestigio de la escritura de los intelectuales y escritores. Y, sin duda, la tradición ensayística latinoamericana es prueba de que "el estilo es la idea" (el título del libro de Alberto Paredes sobre el ensayo literario hispanoamericano en el siglo XX, publicado en 2008), así como alguna vez se pudo decir la célebre 
frase "el estilo es el hombre" (Buffon, Discours sur le Style, Académie Française, 1753).

En esta misma línea, es necesario considerar que, en el campo de las humanidades, la escritura y la comunicación del conocimiento son necesariamente situadas, y su autor sabe que debe reconocer sus espacios, sus límites y la tradición a la que se adscribe, quizás más aún cuando escribe sobre temas y asuntos que van más allá del ámbito puramente local. Por eso, para un académico chileno, en nuestro caso, el escribir para que su publicación aparezca en un índice norteamericano, es sin duda provechoso desde el punto de vista de su carrera académica, pero no es siempre algo esencial para su reconocimiento en el ámbito más cercano. De hecho, el impacto que es realmente significativo, el que va más allá del número de citas, puede encontrarse en otro tipo de formato y de medio de publicación que no necesariamente es una revista indexada.

No quisiera hacer aquí la apología del ensayo en desmedro del artículo científico. Solo intento mostrar que en las distintas áreas de las humanidades y las ciencias sociales, se ha conservado y se debería conservar la diversidad de los formatos en los que se comunican los resultados de la investigación y de la reflexión, independientemente de las necesidades inmediatas de los procesos de evaluación curricular, o bien, se debería intervenir más efectivamente en esos procesos con el objetivo de transformarlos.

Es fácil comprobar que cualquier ansiedad homogeneizadora, como la que podemos observar en los comités de las universidades y en los centros que asignan los recursos para la investigación, no hace sino estandarizar la capacidad investigadora de los académicos. Y el efecto de la estandarización y de la homogeneidad como objetivo final no me parece tan perjudicial para los investigadores en humanidades (quienes suelen tener la flexibilidad de toda especie "sobreviviente"), sino quizás, paradójicamente, para los que se sienten más cómodos en el formato hegemónico. Es cierto que se reconoce una jerarquía y un rango al interior de las revistas indizadas en cuanto a su calidad, pero también es real que, en el circuito que hemos descrito, lo más importante es el impacto de las citas; me pregunto si eso puede significar, a la larga, que se haga cada vez más difícil valorar adecuadamente la calidad de los aportes.

Por último, es necesario considerar que el ordenamiento de las palabra y de los discursos en nuestro actual sistema tiene un alcance muy significativo en lo que respecta al pensamiento y a la reflexión en humanidades y, más en 
general, implica cierta concepción del saber sobre la que se hace imprescindible debatir y reflexionar. Como lo ha planteado Santos Herceg,

“...en la medida en que se ha instalado una determinada idea acerca de lo que es el "saber" en el ámbito de las Humanidades, dicha concepción va respaldada, fortificada, si se quiere, por una cierta institucionalidad que exige una organización desde donde se impone un determinada administración de los discursos.

"La sospecha aquí es que la finalidad de esta organización es aligerar de su peligrosidad al discurso que circula sin restricciones, controlando, ordenando, lo que Foucault llama "los juegos del pensamiento y de la lengua" 6 . El filósofo francés habla de que en el fondo late una "Logofobia" -oculta subrepticiamente tras una aparente "Logofilia" -. El paper (...) me parece un caso paradigmático de esta "logofobia", un ejemplo actual y contundente de una forma de controlar la peligrosidad del discurso de las Humanidades en general, de dominar su proliferación, de organizar su incontrolabilidad mediante prohibiciones, barreras, límites y reglas"8.

\section{ELOGIO DEL ENSAYO}

Para concluir, quisiera hacer un elogio del ensayo como fuente de placer, más allá de su valor para la evaluación de la investigación en humanidades. Mi elogio tiene que ver con la experiencia comparada de la lectura de artículos científicos y de los ensayos en mi área de competencia, la de los estudios literarios; los textos más claramente adscritos al formato del paper me han

\footnotetext{
"Todo pasa como si prohibiciones, barreras, límites, se dispusieran de manera que se domine, al menos en parte, la gran proliferación del discurso, de manera que su riqueza se aligere de la parte más peligrosa y que su desorden se organice según figuras que esquivan lo más incontrolable; todo pasa como si se hubiese querido borrar hasta las marcas de su irrupción en los juegos del pensamiento y de la lengua" (Foucault, Michel. El orden del discurso. Alberto González T. (trad.). Barcelona: Ediciones Fábula, 2002:50, cit. por Santos Herceg, p. 201).

"(...) una especie de sordo temor contra esos acontecimientos, contra esa masa de cosas dichas, contra la aparición de todos esos enunciados, contra todo lo que pueda haber allí de violento, de discontinuo, de batallador, y también de desorden y de peligro, contra ese gran murmullo incesante y de desordenado de discurso" (Foucault, 2002: 51, cit. por Santos Herceg, p. 201).
}

$8 \quad$ Santos Herceg, José, “Tiranía del paper...”, p. 201. 
servido siempre como apoyo, para confirmar o refutar un conocimiento establecido, y solo en ocasiones excepcionales, para abrir nuevos caminos. A la inversa, la "libertad" del ensayo histórico o literario, una libertad fundada, por cierto, en el rigor y las exigencias de coherencia y pertinencia disciplinarias, permite justamente ir más allá de los conocimientos transmitidos $\mathrm{y}$, por lo mismo, nos permite volver a jugar creativamente con las ideas, recordando en este punto las palabras de Michel Foucault sobre "los juegos del pensamiento y la lengua" que mencionamos más arriba (El Orden del discurso, p. 50).

En mi perspectiva, por lo mismo, la lectura ligada a la investigación en humanidades permite un modo específico de conocimiento gozoso que es muy semejante a aquella experiencia plena que recrea Borges cuando escribe del mundo de los libros en su cuento "La Biblioteca de Babel":

“...La Biblioteca es total $[\ldots]$ en sus anaqueles se registra todo lo que es dable expresar: en todos los idiomas. Todo: la historia minuciosa del porvenir, las autobiografías de los ángeles, el catálogo fiel de la Biblioteca, miles y miles de catálogos falsos, la demostración de la falacia de esos catálogos, [...]la relación verídica de tu muerte [...]. Cuando se proclamó que la Biblioteca abarcaba todos los libros, la primera impresión fue de extravagante felicidad. Todos los hombres se sintieron señores de un tesoro intacto y secreto".

Si hemos leído el cuento de Borges hasta el final, nos damos cuenta de que su Biblioteca de Babel, interminable y sin límites reconocibles, no es precisamente el lugar donde reside la felicidad humana. Pero al comentar estas líneas que acabo de citar, el historiador de la escritura y de la lectura que es Roger Chartier, ve en esta Biblioteca de Babel borgiana un sueño que ha atravesado la historia europea y occidental, en la búsqueda de una biblioteca que reúna todos los saberes acumulados, todos los libros jamás escritos. Ese sueño, escribe Chartier, "fundó la constitución de las grandes "bibliotecas", ya fueran reales, eclesiásticas o privadas; justificó la búsqueda tenaz de los libros raros, de los textos perdidos, de los textos desaparecidos. Gobernó el gesto arquitectónico dedicado a construir edificios capaces de acoger la memoria del mundo" 9 .

9 Roger Chartier. "Bibliotecas sin muros". El orden de los libros, Barcelona: Gedisa Editorial 2000, (1992), pp. 69-70. 
Este sueño, dice también Chartier, es el que justifica los grandes sistemas de clasificación de bibliotecas, que no son sino un ejemplo de los dispositivos del poder y del orden sobre los libros, pero también sobre nuestras lecturas, hasta el día de hoy.

Ese poder pareciera estar ahora más centrado en la producción y jerarquización de los artículos que ya hemos descrito, en su relación con la profesión académica y el ordenamiento de los saberes en el mundo universitario, en particular.

Por lo mismo, pienso que la supervivencia del libro y del ensayo en el ámbito de las humanidades y de las ciencias sociales nos señala la necesidad de mantener la diversidad de nuestras formas de decir y de escribir los saberes propios de estas disciplinas. En este sentido, es vital permitir que la investigación recupere siempre de nuevo esta dimensión: la libertad y el placer del conocimiento que impide que convirtamos el trabajo apasionante de la investigación y la reflexión en una tarea hecha "por obligación". Y, por cierto, debemos estar también atentos a la aparición de otras formas de comunicación del conocimiento, a las que deberíamos estar siempre abiertos. 